\title{
An analysis of the differentiation rules and influencing factors of venture capital in Beijing-Tianjin-Hebei urban agglomeration
}

\author{
FANG Jiawen \\ Department of Urban Planning, Luskin School of Public Affairs, University of California, Los Angeles, \\ CA 90095-1656, USA
}

\begin{abstract}
Under China's innovation-driven development strategy, venture capital has become an important driving force in urban agglomeration integration and collaborative innovation. This paper uses social network analysis to analyze spatiotemporal differences of venture capital in the Beijing-Tianjin-Hebei urban agglomeration for the period 2005-2015. A gravity model and panel data regression model are used to reveal the influencing factors on spatiotemporal differences in venture capital in the region. This study finds that there is a certain cyclical fluctuation and uneven differentiation in the venture capital network in the Beijing-Tianjin-Hebei urban agglomeration in terms of total investment, and that the three centers of venture capital (Beijing, Shijiazhuang and Tangshan) have a stimulatory effect on surrounding cities; flows of venture capital between cities display certain networking rules, but they are slow to develop and strongly centripetal; there is a strong positive correlation between levels of information infrastructure development and economic development and venture capital investment; and places with relatively underdeveloped financial environments and service industries are less able to apply the fruits of innovation and entrepreneurship and to attract funds. This study can act as a reference for the Beijing-Tianjin-Hebei urban agglomeration in building a world-class super urban agglomeration with the best innovation capabilities in China.
\end{abstract}

Keywords: venture capital; Beijing-Tianjin-Hebei urban agglomeration; differentiation; influencing factors; gravity model

Venture capital (VC) is a relatively new form of financing that plays an important part in innovation projects, the application of innovations in industry, market development and business management. Essentially, it is a system innovation that promotes technological innovation and industrial change. Both governments and academic departments currently lack an authoritative explanation of the role of VC, with the systematic and representative view defined by the US National Venture Capital Association: venture capital is a type of equity capital involving investment by financiers in highly competitive emerging growth compa-

Received: 2017-06-06 Accepted: 2017-08-10

Foundation: Major Program of the National Natural Science Foundation of China, No.41590842

Author: Fang Jiawen (1993-), Master's Candidate, specialized in urban development and planning.

E-mail: fangjiawen@g.ucla.edu 
nies. $\mathrm{VC}$ is the application of professional management and equity investment in emerging unlisted companies in search of growth (Hellmann, 2000).

The China Venture Capital Development Report divides VC investment institutions into three categories: the first is VC companies (i.e. VC funds, including companies set up by governments that are $\mathrm{VC}$ guide funds); second is $\mathrm{VC}$ management companies (which are entrusted by companies to invest $\mathrm{VC}$, select investment projects, provide investment decisions and suggestions, and are entrusted to carry out post-investment management); and third is a small number of public institutions engaged in government $\mathrm{VC}$ operations (some of which directly use government funds to invest in projects and some of which guide $\mathrm{VC}$ funds, with equity participation or investment by $\mathrm{VC}$ companies acting as a sort of subsidy).

Following its call for "mass entrepreneurship and innovation" in 2014, the Chinese government has gradually increased its support in these areas. The State Council has held nearly 20 executive meetings to discuss implementation of relevant policies and has issued 22 documents on topics including finance, the market and scientific research, explaining supporting policies and specific implementation measures for innovation and entrepreneurship activities. This reflects the new trend in China's economic transformation of seeking innovation-driven growth, as well as the gradual implementation of its strategic goal to become an innovation powerhouse by 2020 .

In addition, the CPC Central Committee has decided to promote the coordinated development of Beijing, Tianjin and Hebei. To this end, the Political Bureau of the CPC Central Committee approved the Beijing-Tianjin-Hebei Coordinated Development Plan on April 30, 2015, which proposed establishing the Collaborative Innovation Community Planning and Development Program. It also proposed improving the status of the Beijing-Tianjin-Hebei Scientific and Technological Innovation Center by 2017 through significant improvements in its regional collaborative innovation capabilities and application rate of innovations, increasing investment in science and technology and $R \& D$ spending to $3.5 \%$ of regional GDP, and having an innovation-driven community with a clear division of labor and efficient industry and innovation chains in the region by 2020 .

VC can simultaneously promote technological and institutional innovation. It also has strong liquidity and has become an important link for connecting cities. Back when the Beijing Municipal Government issued the Opinions on Implementing the 'Outline Beijing-Tianjin-Hebei Coordinated Development Plan', it was made clear that the aim was to promote integration of the investment and financing markets of Beijing, Tianjin and Hebei, and to establish a capital security system.

\section{Research scope and data sources}

\subsection{Research scope}

The research scope of this paper is the Beijing-Tianjin-Hebei urban agglomeration, which comprises two large municipalities directly under the central government (Beijing and Tianjin) and 11 prefecture-level cities (Shijiazhuang, Tangshan, Baoding, Langfang, Handan, Cangzhou, Hengshui, Xingtai, Qinhuangdao, Zhangjiakou and Chengde). The agglomeration is a network of cities with a compact spatial configuration and close economic ties based on highly-developed transport and communication infrastructure, giving it a high level of urban 
integration (Fang et al., 2010). Such high-level integration is reflected in six major areas: regional industrial development and layout, infrastructure construction, regional market development, coordinated urban and rural planning and development, environmental protection and ecological restoration, as well as social development and basic public services (Fang et al., 2015). The network relationships between cities in the agglomeration include "hardware networks", primarily based on infrastructure, and "software networks", primarily based on flows of people, goods, information and capital.

Becoming a multi-center and network-based urban agglomeration is an inevitable trend in the economic development of the Beijing-Tianjin-Hebei agglomeration, with both competition and cooperation between cities. The closely linked spatial structure and the city networks re-enhanced each other over time (Batten, 1995; Parr, 2010). Many scholars have already used social network analysis methods to analyze economic links within urban agglomerations. Hou et al. (2009), Li (2011) and Fang (2013) used social network analysis to study the economic integration and network structure of the Yangtze River Delta urban agglomeration. Wang et al. (2011) used social network analysis to examine the coordinated development of the Guanzhong-Tianshui Economic Zone. Liu and Dai (2013) used social network analysis to study the economic network of the Poyang Lake urban agglomeration. Zhao et al. (2014) used complex network methods to look at economic links in the producer service industry, general service industry and manufacturing industry of the Beijing-Tianjin-Hebei urban agglomeration. Lu et al. (2015) used special network analysis methods and a gravity model to examine the network structure of the Beijing-Tianjin-Hebei urban agglomeration.

Most of these studies focused on macroeconomic factors, and those that have focused on the subsector of VC were at the national scale. For example, a study by Green and McNaughton (1989) revealed New York's dominance in the US VC network using a traditional gravity model to analyze the links between cities. Zhang (2011) analyzed Chinese VC city networks and found that in China's current institutional environment the proximity of social relations (such as the establishment of syndicate alliances) plays a greater role in building trust, sharing resources and avoiding risks. Wang et al. (2014) used social network analysis methods to analyze the spatial organization of a $\mathrm{VC}$ city network and found that supply and demand within the VC industry in China has created a VC city network with Beijing and Shanghai as core nodes. Qiu (2012) studied China's VC city network from various perspectives, including network centrality, clustered sub-agglomerations and urban network distribution characteristics, to obtain a multi-level network system, and used a gravity model to investigate the radial scope of VC investment in Beijing, Shanghai and Shenzhen.

Most of these studies on links between urban agglomeration networks are macroscopic, and most of them employ comprehensive indices to carry out analysis. But they fail to look at the structural characteristics and influencing mechanisms of city networks. Based on previous macroscopic research, this paper analyzes the spatiotemporal distribution of $\mathrm{VC}$ in the Beijing-Tianjin-Hebei urban agglomeration and then uses a gravity model and econometric analysis model to reveal influencing mechanisms.

\subsection{Data sources}

Within the context of the Chinese government's proposal to implement an innovation-driven 
development strategy and the Beijing-Tianjin-Hebei coordinated development strategy, this paper employs data on VC investment cases from the Zero 2 IPO Group ${ }^{1}$ and uses social network analysis methods to analyze the spatiotemporal differentiation rules of resource sharing and flows between the cities of the Beijing-Tianjin-Hebei urban agglomeration from the perspective of VC.

Specific research data is from the Zero 2 IPO Group. This comprises data from 40,402 VC cases in China (including Hong Kong, Macau and Taiwan) between 2005 and 2015. It includes the location of investors and financing parties, organization names, industry classifications, and investment stages, amounts and dates. It contains original data on a total of 6,058 VC cases in the Beijing-Tianjin-Hebei urban agglomeration from 2005 to 2015, which is used in this study.

\section{Analysis of the differentiation rules for venture capital in the Beijing- Tianjin-Hebei urban agglomeration}

\subsection{Anomalous cyclical fluctuations in total venture capital investment}

An analysis of the statistics shows that VC investment in the Beijing-Tianjin-Hebei urban agglomeration accounts for approximately $30 \%$ of China's total and has a cyclical fluctuation of about four years. In 2005, 2009 and 2013, total VC investment was relatively high and then began to decline, reaching a trough, followed by a rapid recovery, in the last year of each cycle. In general, the extent of fluctuations within cycles has increased. This can be seen in the fact that $\mathrm{VC}$ investment in the agglomeration as a proportion of the national total in the first year of the final cycle (2013) was at its highest level (63\%) for 10 years, but it decreased to its lowest level of $12 \%$ (see Figure 1) in the last year of the final cycle. However, as VC investment carries a certain degree of risk, due to greater exposure to economic uncertainty compared to other forms of investment, it also displays anomalous cyclical fluctuations.

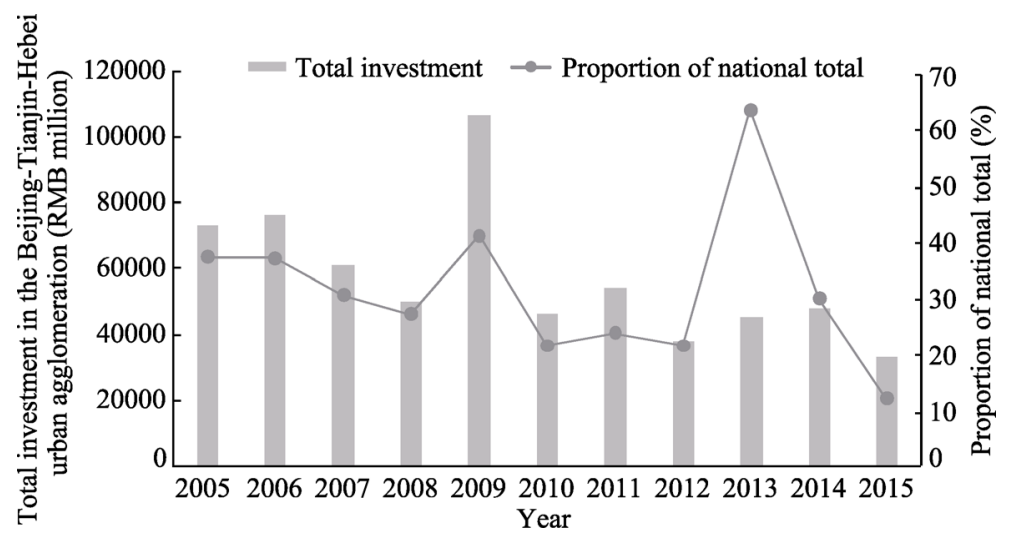

Figure 1 Total annual venture capital investment in the Beijing-Tianjin-Hebei urban agglomeration

\subsection{Significant spatial imbalance in total venture capital investment}

The spatial distribution of VC investment in the Beijing-Tianjin-Hebei urban agglomeration

\footnotetext{
${ }^{1} \mathrm{http}: / / \mathrm{www}$. pedata.cn/
} 
is greatly influenced by the interaction of various factors like innovations, capabilities and infrastructure, which resulted in a significantly imbalanced spatial structure. Specifically, cities in the south of the urban agglomeration have higher VC investment than cities in the north. Moreover, Beijing, which has China's highest concentration of VC investment, shows strong cyclicality. The city also hosts the most innovation events, making it the biggest innovation center in the Beijing-Tianjin-Hebei urban agglomeration and the largest recipient of VC investment. Between 2005 and 2015, Beijing consistently attracted more than $90 \%$ of total VC investment in the Beijing-Tianjin-Hebei urban agglomeration, reflecting its core position within the agglomeration. Shijiazhaung - the capital of Hebei Province - ranked second in the agglomeration for its share of $\mathrm{VC}$ investment, though the proportion was very small compared to Beijing, at only $5 \%$ or so. None of the other cities in the agglomeration attracted more than $2 \%$ of $\mathrm{VC}$ investment individually.

In 2005, VC investment in the Beijing-Tianjin-Hebei urban agglomeration was concentrated in just three cities (the "three centers"): Beijing, Shijiazhuang and Tangshan. For the period 2005-2015, the spatial distribution of VC investment extended out from these three major concentrations toward surrounding cities, such as Langfang, Tianjin and Hengshui, which experienced rapid growth in VC investment. Following a decade of development and changes, it can be seen that VC investment developed slowly in cities in the north of the agglomeration and rapidly in cities in the south and central regions of the agglomeration. There was also an obvious stimulatory effect from VC investment in Beijing and Shijiazhuang, while Tangshan and Qinhuangdao slipped down the rankings and Tianjin rose up the rankings (see Table 1 and Figures 2 and 3).

\subsection{Gradual shift in network density of venture capital investment from Beijing to periphery}

Network density describes the ratio of nodes in a network that are actual connections. It indicates the cohesiveness of a network and degree of connection between various points (Liu, 2014). In this study, the number of VC connections between cities in the sample area was used to measure the density of the city network. The following is the formula used, in which $D$ is network density, $n$ is the number of actors and $m$ is the actual number of connections in the network (UCINET network analysis software can directly calculate the network density of the whole network):

Where the whole network is made up of non-directional connections:

$$
D=\frac{2 m}{n(n-1)}
$$

Where the whole network is made up of directional connections:

$$
D=\frac{m}{n(n-1)}
$$

The calculations show that changes in the overall network density of VC investment in the Beijing-Tianjin-Hebei urban agglomeration have some similarities with changes in the total amount of $\mathrm{VC}$ investment, also with a four-year fluctuation period, but that the peak value of VC network density has a lag of one year compared to total VC investment (density peak values were reached in 2007, 2010 and 2014, whereas total peak values were reached in 
2006, 2009 and 2013). The reason for this may be that Beijing and Tianjin developed rapidly in the initial stage of each VC investment cycle (with frequent investment and financing events in the cities), which gradually radiated out to other cities in the agglomeration.

Table 1 Share of venture capital investment of each city in Beijing-Tianjin-Hebei (BTH) urban agglomeration

\begin{tabular}{|c|c|c|c|c|c|c|c|c|c|c|c|c|}
\hline \multirow[b]{2}{*}{ City } & \multicolumn{4}{|c|}{2005} & \multicolumn{4}{|c|}{2010} & \multicolumn{4}{|c|}{2015} \\
\hline & $\begin{array}{c}\text { Total } \\
\text { VC }\end{array}$ & $\begin{array}{c}\% \text { of } \\
\text { national } \\
\text { total }\end{array}$ & $\begin{array}{l}\% \text { of } \\
\text { ВTH }\end{array}$ & $\begin{array}{l}\text { Rank } \\
\text { in } \\
\text { BTH }\end{array}$ & $\begin{array}{c}\text { Total } \\
\text { VC }\end{array}$ & $\begin{array}{c}\% \text { of } \\
\text { national } \\
\text { total }\end{array}$ & $\begin{array}{l}\% \text { of } \\
\text { ВTH }\end{array}$ & $\begin{array}{l}\text { Rank } \\
\text { in } \\
\text { BTH }\end{array}$ & $\begin{array}{c}\text { Total } \\
\text { VC }\end{array}$ & $\begin{array}{c}\% \text { of } \\
\text { national } \\
\text { total }\end{array}$ & $\begin{array}{l}\% \text { of } \\
\text { BTH }\end{array}$ & $\begin{array}{l}\text { Rank } \\
\text { in } \\
\text { BTH }\end{array}$ \\
\hline Beijing & 142349.7 & 36.1 & 97.1 & 1 & 86339.3 & 19.8 & 92.1 & 1 & 63527.8 & 11.4 & 94.3 & 1 \\
\hline Tianjin & 0.0 & 0.0 & 0.0 & 10 & 40.0 & 0.0 & 0.0 & 9 & 214.7 & 0.0 & 0.3 & 5 \\
\hline Shijiazhuang & 1849.2 & 0.5 & 1.3 & 2 & 5079.0 & 1.2 & 5.4 & 2 & 2684.8 & 0.5 & 4.0 & 2 \\
\hline Baoding & 300.0 & 0.1 & 0.2 & 5 & 300.0 & 0.1 & 0.3 & 5 & 297.0 & 0.1 & 0.4 & 4 \\
\hline Cangzhou & 250.0 & 0.1 & 0.2 & 6 & 250.0 & 0.1 & 0.3 & 6 & 16.0 & 0.0 & 0.0 & 9 \\
\hline Chengde & 0.0 & 0.0 & 0.0 & 10 & 0.0 & 0.0 & 0.0 & 13 & 4.0 & 0.0 & 0.0 & 12 \\
\hline Hengshui & 48.0 & 0.0 & 0.0 & 8 & 48.0 & 0.0 & 0.1 & 8 & 205.0 & 0.0 & 0.3 & 6 \\
\hline Langfang & 0.0 & 0.0 & 0.0 & 10 & 15.0 & 0.0 & 0.0 & 11 & 14.5 & 0.0 & 0.0 & 10 \\
\hline Tangshan & 1250.6 & 0.3 & 0.9 & 3 & 1232.9 & 0.3 & 1.3 & 3 & 30.4 & 0.0 & 0.0 & 7 \\
\hline Xingtai & 20.0 & 0.0 & 0.0 & 9 & 20.0 & 0.0 & 0.0 & 10 & 18.9 & 0.0 & 0.0 & 8 \\
\hline Qinhuangdao & 126.7 & 0.0 & 0.1 & 7 & 126.7 & 0.0 & 0.1 & 7 & 6.0 & 0.0 & 0.0 & 11 \\
\hline Handan & 349.2 & 0.1 & 0.2 & 4 & 330.0 & 0.1 & 0.4 & 4 & 330.2 & 0.1 & 0.5 & 3 \\
\hline Zhangjiakou & 0.0 & 0.0 & 0.0 & 10 & 10.0 & 0.0 & 0.0 & 12 & 0.0 & 0.0 & 0.0 & 13 \\
\hline
\end{tabular}

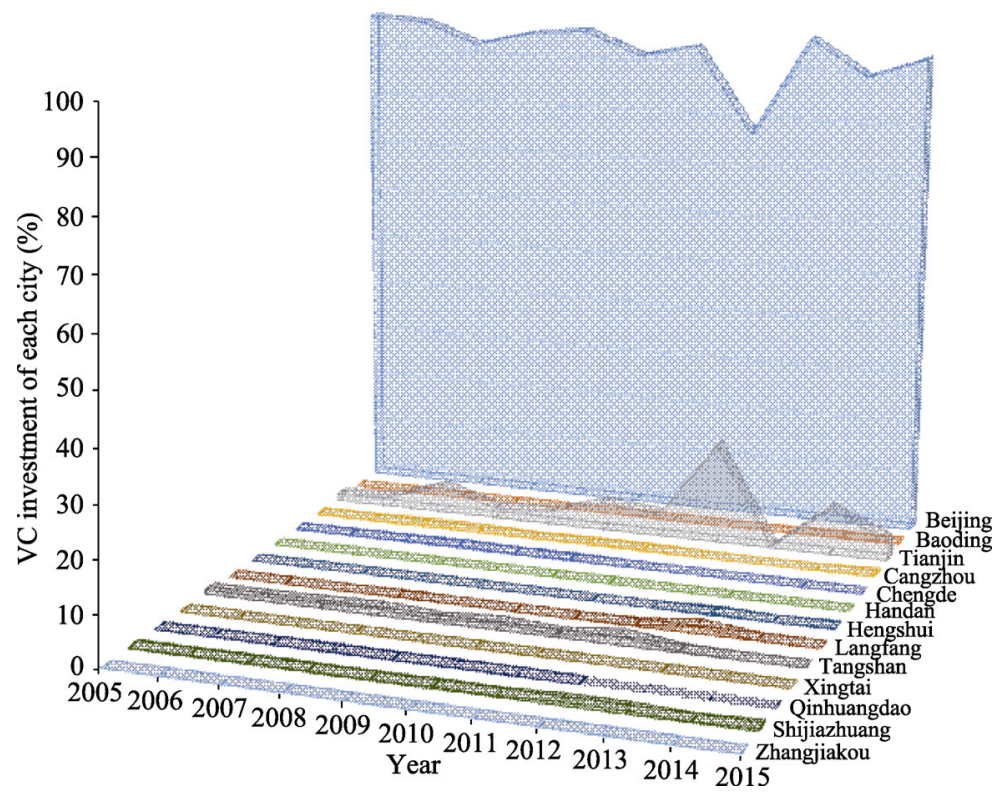

Figure 2 Annual changes in venture capital investment in cities of the Beijing-Tianjin-Hebei urban agglomeration 

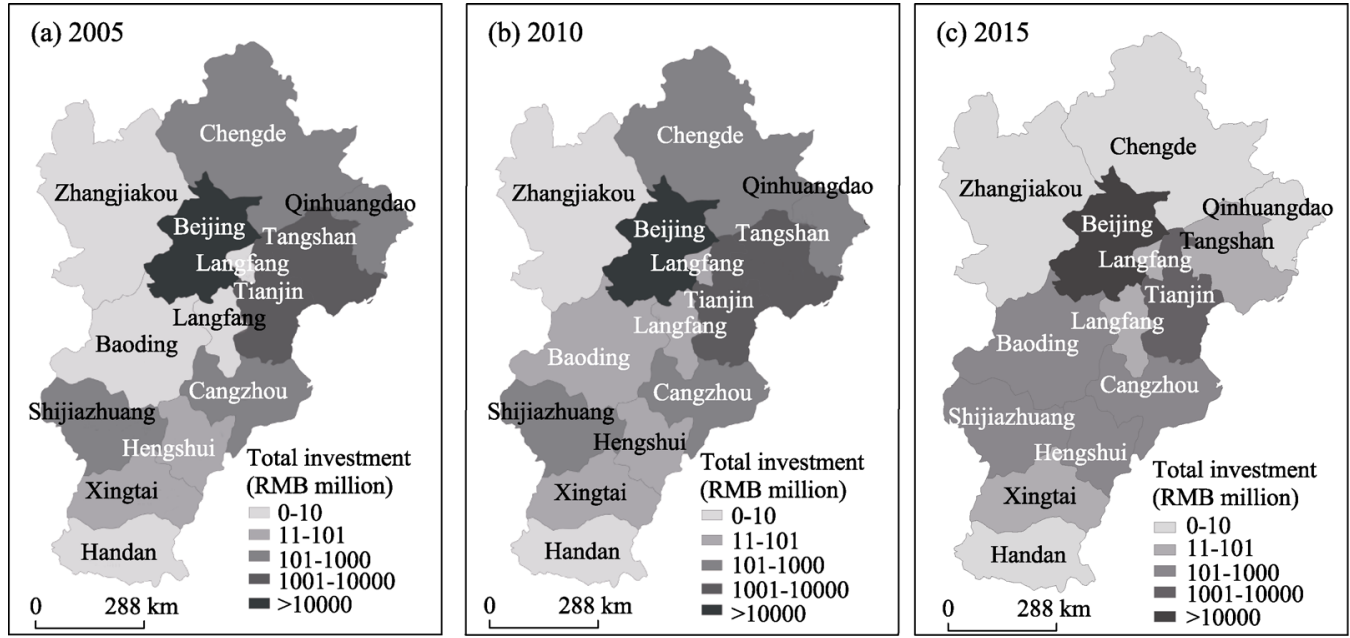

Figure 3 Spatiotemporal distribution of venture capital in the Beijing-Tianjin-Hebei urban agglomeration

Looking at the spatial distribution of VC flows between cities in the agglomeration, connections between cities in the southeast of the agglomeration developed relatively quickly, and increases in VC network density were mainly concentrated in that area. Although VC network density increased, it was strongly centripetal on the whole, VC investment connections mostly emanated from Beijing directly to other cities within the cluster, and there were relatively few VC investment connections between the other cities. There were minor VC flows between Shijiazhuang, Tianjin, Tangshan and Langfang, but the amounts were small, with low stability of VC connections and a very weak stimulatory effect on surrounding cities (see VC network in Figure 4).
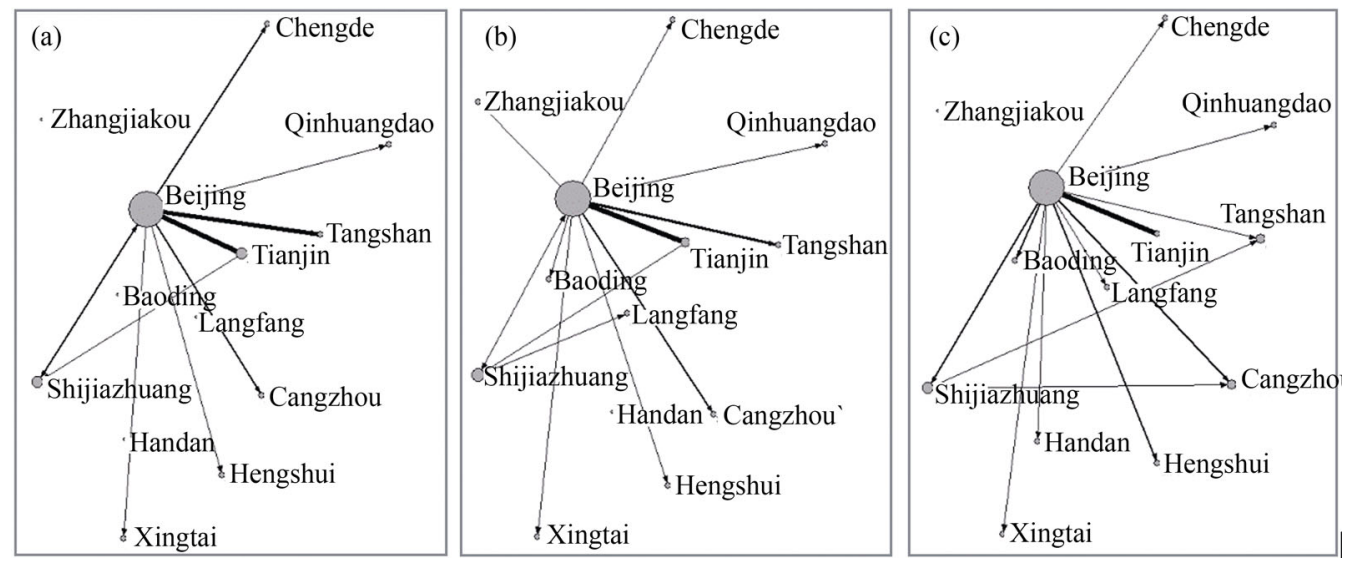

Figure 4 Venture capital network connections between cities in the Beijing-Tianjin-Hebei urban agglomeration

\subsection{Cyclical fluctuations of venture capital investment in different stages of entrepre- neurial projects}

The VC investment process differs depending on the current stage of the company being invested in. The different stages are seed, start-up, expansion, maturity and reorganization. Statistics on structural changes in VC investment during different stages of entrepreneurial 


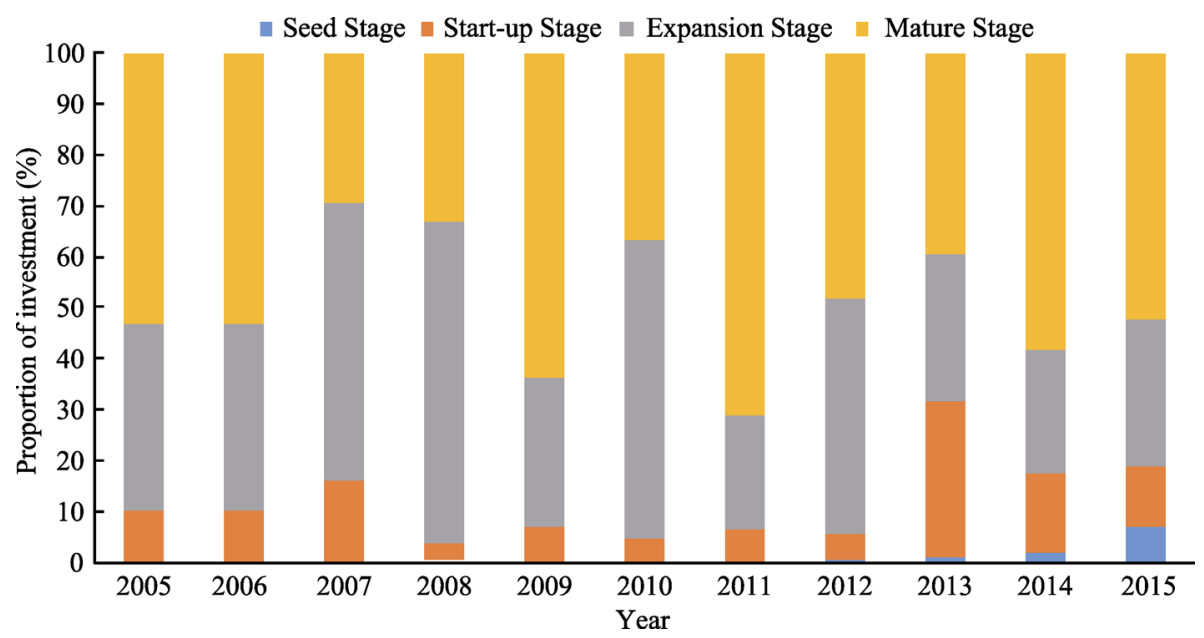

Figure 5 Distribution of venture capital in different stages of companies

projects can be seen in Figure 5 below. In general, during the period 2005-2015, investment was mainly concentrated in companies in the expansion and maturity stages, which indicates that there is a relatively significant funding gap for companies in the first two stages of company creation, particularly in the seed stage. This can be explained as being due to a relatively conservative $\mathrm{VC}$ investment environment in the Beijing-Tianjin-Hebei urban agglomeration, with investment favoring more mature and less risky ventures. Looking at changes over time, the proportion of investment in seed and start-up stages fluctuated but increased on the whole, particularly the proportion of investment in seed-stage ventures from 2014 onwards, which reflects the positive impact of national innovation and entrepreneurship policies on investment behavior. In terms of structural changes to investment stages, investment in the first two stages and the latter two stages had a two-to-three-year fluctuation period. On the one hand, venture projects usually take two years to move from the seed to the mature stage, with the vast majority of investment projects continuing to receive investment through the different stages until the company is listed, at which point investment switches to the next round of new projects. On the other hand, there is also a certain degree of adjustment in capital markets in response to the assessment of risk, creating periods when investors are more conservative and are more likely to invest in mature projects. Success with mature projects then leads investors to take bigger risks and begin investing in start-ups again.

\section{Quantitative analysis of the factors in the spatiotemporal variability of venture capital in the Beijing-Tianjin-Hebei urban agglomeration}

The spatiotemporal distribution of $\mathrm{VC}$ in the Beijing-Tianjin-Hebei urban agglomeration shows network characteristics, though these are not obvious, and they developed slowly during the period 2005-2015. What is the cause of this phenomenon? What factors influence VC connections between cities in the Beijing-Tianjin-Hebei urban agglomeration? To answer these questions, a gravity model and panel data regression model were used.

VC connections are, by their very nature, economic links between cities, and they consist of a type of interacting force (gravity) between cities. Factors that influence the VC city network structure were chosen for this study. A gravity model translated corresponding at- 
tribute data into relational data and created a simulated urban gravity network with different attributes. A regression analysis was also carried out using the quantitative analysis software STATA, which revealed the influencing factors in the formation and evolution of the Beijing-Tianjin-Hebei urban agglomeration's VC network.

\subsection{Indicator selection and urban gravity model for the quantitative analysis of influencing factors}

For the purposes of this study, five factors that influence the structural formation and evolution of VC city networks were selected, namely level of urban economic development, level of tertiary industry development, level of information infrastructure development, comprehensive innovation capability and level of financial environment development (see Table 2), in order to understand the formation and evolution mechanisms of $\mathrm{VC}$ investment in the Beijing-Tianjin-Hebei urban agglomeration.

Of these factors, level of urban economic development provides a good foundation for regional VC development, and it is one of the most important factors affecting VC investment in the Beijing-Tianjin-Hebei urban agglomeration. In their studies on regional differences, Chen et al. (2010) and Qiu (2011) used per capita GDP as an important indicator of the level of regional economic development. A city's GDP reflects its overall economic strength, whereas per capita GDP better reflects a city's level of economic development, and it eliminates the influence of population size. As such, this study uses per capita GDP to indicate levels of urban economic development.

The level of tertiary industry development indicates the presence of the right soft environment for the development and concentration of VC (Ji, 2007). The level of tertiary industry development is closely related to $\mathrm{VC}$ investment as it indicates the presence of capital market intermediaries, including patent firms, accountants, auditors, law firms, asset appraisal agencies, information consultants and investment banks. As such, this study uses the proportion of production value of the tertiary industry as the corresponding indicator of tertiary industry development.

Table 2 Corresponding data indicators and explanations for influencing factors of venture capital in the Beijing-Tianjin-Hebei urban agglomeration

\begin{tabular}{lllll}
\hline Variable type & \multicolumn{1}{c}{ Variable name } & $\begin{array}{c}\text { Data processing } \\
\text { method }\end{array}$ & Corresponding data indicator & Data source \\
\hline $\begin{array}{l}\text { Dependent } \\
\text { variable } V C\end{array}$ & $\begin{array}{l}\text { Investment } \\
\text { intensity } V C\end{array}$ & $\begin{array}{l}\text { Inter-city } \\
\text { investment } V C\end{array}$ & Inter-city investment $V C$ & $\begin{array}{l}\text { Zero 2 IPO Group } \\
\text { China City Statisti- } \\
\text { cal Yearbook }\end{array}$ \\
$\begin{array}{llll}\text { Independent } \\
\text { variable } G\end{array}$ & $\begin{array}{l}\text { Economic } \\
\text { Strength } G E\end{array}$ & $G E_{i j}=E_{i} E_{j} e^{-d_{i j}}$ & GDP $E$ & $\begin{array}{l}\text { China City Statisti- } \\
\text { cal Yearbook }\end{array}$ \\
& $\begin{array}{l}\text { Service Strength } \\
G S\end{array}$ & $G S_{i j}=S_{i} S_{j} e^{-d_{i j}}$ & Proportion of tertiary industry $S$ & $\begin{array}{l}\text { China City Statisti- } \\
\text { cal Yearbook }\end{array}$ \\
& $\begin{array}{l}\text { Communication } \\
\text { Strength } G T\end{array}$ & $G T_{i j}=T_{i} T_{j} e^{-d_{i j}}$ & $\begin{array}{l}\text { Number of telephone and Internet } \\
\text { users } T\end{array}$ & $\begin{array}{l}\text { China City Statisti- } \\
\text { cal Yearbook }\end{array}$ \\
& $\begin{array}{l}\text { Innovation } \\
\text { Strength } G C\end{array}$ & $G C_{i j}=C_{i} C_{j} e^{-d_{i j}}$ & $\begin{array}{l}\text { Number of patents } C \text { (including } \\
\text { invention patents, appearance } \\
\text { designs and utility models) }\end{array}$ & $\begin{array}{l}\text { China Patent Data- } \\
\text { base }\end{array}$ \\
& $\begin{array}{l}\text { Financial } \\
\text { Strength } G F\end{array}$ & $G F_{i j}=F_{i} F_{j} e^{-d_{i j}}$ & $\begin{array}{l}\text { Total deposits and loans of finan- } \\
\text { cial institutions at end of year } F\end{array}$ & $\begin{array}{l}\text { China City Statisti- } \\
\text { cal Yearbook }\end{array}$ \\
\hline
\end{tabular}


The level of information infrastructure development is important due to VC's heavy reliance on information availability. In previous studies, this influencing factor has not been tested or analyzed, and only transport and postal services are generally included in regression analysis. However, given today's information society and the high-risk nature of $\mathrm{VC}$, it is necessary to separate this factor and study it separately. As a result, this paper will include this influencing factor in its model framework and use total numbers of telephone (mobile and fixed-line) and Internet users as the corresponding indicator of the level of information infrastructure development.

Urban comprehensive innovation capability reflects, to a certain extent, the potential of a city to develop and change. The number of patents reflects a city's scientific and technological level, and variables related to scientific and technological level play an extremely significant role in VC institutions selecting investment locations. A high scientific and technological level in a region can bring more opportunities and attract more $\mathrm{VC}$ investors to invest in that place. Therefore, this study uses annual published patents (including invention patents, appearance designs and utility models) as the corresponding indicator of comprehensive innovation capability.

VC is essentially a new financial system arrangement, so it is directly affected by the structure of the financial system, the development situation of financial markets and the operational efficiency of the financial system. China's financial environment depends largely on the level of development of the commercial banking system. Commercial banks are important institutions for the government to regulate economic development, and they have become the source of the vast majority of loans with VC attributes to the new and high-tech industries. This study, therefore, uses the amount of financial institution loans to indicate the level of financial environment development.

The above five indicators are the attribute data for urban nodes. In this study, a gravity model is used to transform attribute data into relation data between cities and construct five types of gravity networks between cities with different attributes: Economic Strength GE, Service Strength GS, Communication Strength GT, Innovation Strength GC and Financial Strength GF. The gravity model used is based on Alan G. Wilson's entropy-maximizing gravity model in accordance with the negative exponential law, which has the following formula:

$$
F_{i j}=K P_{i} P_{j} e^{-b d_{i j}}
$$

where $F_{i j}$ is the interaction between cities, $P_{i}$ and $P_{j}$ are city attributes, $d_{i j}$ is the distance between cities, and $K$ and $b$ are constants. Compared to traditional exponential models, the negative exponential model has the advantage that when the distance between cities is 0 , the value of $F$ is still meaningful - the strength of the link between cities with the same attributes and zero distance between them can be equivalent to the links within cities, so analyses of interactions within cities and between cities can be classified in the same system.

In terms of the distance variable in the model, this study uses time distance. For actual investment decision-making, time distance is often more valuable than space distance, as highways and railways are the main mode of transportation for investors to move between cities. As a result, the shortest time distances between cities (the lowest value for high-speed 
railways and highways) were selected in this study as the value of $d$ in the gravity model. The distance attenuation coefficient $b$ is usually given as 1 .

Diverse types of city networks interact and coordinate with each other to form a comprehensive city network. To further explore the comprehensive interaction mechanisms between the aforementioned five types of city networks and VC networks, this study uses a regression model based on urban gravity and with annual panel data from 2005 to 2015 . The model is as follows:

$$
V C_{i j}=I_{i j}+\beta_{1} G E_{i j}+\beta_{2} D S_{i j}+\beta_{3} G T_{i j}+\beta_{4} G C_{i j}+\beta_{5} G F_{i j}+\varepsilon_{i j}
$$

where $V C_{i j}$ is the strength of investment links between cities $i$ and $j$, divided into different types of urban gravity between cities $i$ and $j$, and $I$ is the constant term, $\varepsilon_{i j}$ is the residual term and $\beta$ is the regression coefficient of the various urban gravitational forces (see Table 2 for a description of each variable). In the regression model, $V C_{i j}$ uses the present year's investment amount and $G_{i j}$ uses data for the previous year (taking into account the lag in factors producing an effect). Data for each year was standardized before being included in the model. I stands for influencing factors that do not change with time and cannot be directly observed or are difficult to quantify in this model, and is regarded as an "individual effect". There are two ways to deal with an individual effect. One is to regard it as a fixed factor that does not change with time, for which the corresponding model is the "fixed effect" model. The other is to regard it as a random factor, for which the corresponding model is the "random effect" model. There are relatively few individual effects in this model, as the data sample reflects the overall situation in the Beijing-Tianjin-Hebei urban agglomeration, and the conclusion has certain regional characteristics that are not suitable for extrapolating to a larger range; therefore, the fixed effect model is used.

\subsection{Results and discussion of the quantitative analysis of influencing factors}

Table 2 shows the regression analysis results of influencing factors in VC investment for the Beijing-Tianjin-Hebei urban agglomeration, which were derived from a regression model of urban gravity. The significance of each variable in the table was tested, and they had an average significance of over $95 \%$. For the model as a whole, $\mathrm{R}^{2}=0.3511$. This is a very low value, which shows that these five variables cannot fully explain the occurrence and development of VC connections between cities, but they do show the partial formation of mechanisms. The following is a discussion of the results.

3.2.1 Communication Strength $G T$ (level of information infrastructure development) is the most significant positive factor on VC investment between cities, with both a direct and indirect influence.

It can be seen from Table 3 that the regression coefficient of Communication Strength GT (level of information infrastructure development) between cities in the Beijing-Tianjin-Hebei urban agglomeration is $\beta=0.0385$, with a significance of $p<0.001$, which indicates that it is the most significant positive factor on VC investment between cities in the agglomeration, with both a direct and indirect influence. There are two main reasons for this. First, because of the need to minimize risk, VC investment relies heavily on information, which means 
there are increasingly high requirements on the development level of a city's communication network infrastructure. Second, the development of information infrastructure also promotes mobile Internet-related entrepreneurial projects, which attract $\mathrm{VC}$ investment. An analysis of the distribution of VC investment by industry for the years 2005, 2010 and 2015 shows that information transmission, software and information technology services accounted for $6 \%$, $5 \%$ and $27 \%$ of total VC investment in all industries respectively, and $38 \%$ collectively. This included a substantial increase between 2010 and 2015. In recent years, Internet proliferation has increased enormously, especially the use of mobile Internet by traditional industries, which has given birth to a large number of new application models and increased market segmentation. This, in turn, has produced a large number of entrepreneurial projects, which has promoted an increase in VC investment. Information infrastructure development has a limited direct role in developing the $\mathrm{VC}$ industry, but there is a lot of potential for growth of its indirect role (that is, promoting $\mathrm{VC}$ development by developing Internet-related entrepreneurial projects).

Table 3 Results of the panel data regression

\begin{tabular}{lc}
\hline \multicolumn{1}{c}{ Influencing factor } & $\beta$ (Urban gravity regression coefficient) \\
\hline$G E$ (Economic Strength) & $0.0399^{*}$ \\
$G S$ (Service Strength) & $-0.2960^{*}$ \\
$G F$ (Financial Strength) & $-0.0505^{*}$ \\
$G T$ (Communication Strength) & $0.0385^{* * *}$ \\
$G C$ (Innovation Strength) & $-0.1440^{* * *}$ \\
Cons (Constant) & 0.0014 \\
$\mathrm{R}^{2}$ (Overall) & 0.3511 \\
\hline
\end{tabular}

$t$ statistics in parentheses $* p<0.05, * * p<0.01, * * * p<0.001$

3.2.2 Economic Strength $G E$ (level of urban economic development) has a significant positive influence on $\mathrm{VC}$ investment between cities, but the significance is quite low.

The results in Table 3 show that the regression coefficient for Economic Strength GE (level of urban economic development) of cities in the Beijing-Tianjin-Hebei urban agglomeration is $\beta=0.0399$, with a significance of $p<0.05$, which indicates that it has a significant positive influence on $\mathrm{VC}$ investment between cities, but that the significance is quite low. This means that $\mathrm{VC}$ connections in the agglomeration are highly affected by each city's level of economic development. The level of urban economic development reflects, to a considerable extent, the future development prospects of, and current development conditions for, innovative and entrepreneurial projects. Cities with a high level of economic development have a high level of consumption, sound supporting facilities, a rational industrial structure and larger talent pools, making them better able to attract capital. It is a fundamental criterion that influences the decision-making of investors. Nevertheless, studies of VC investment in China have shown a common weak negative correlation between the level of urban economic development and level of VC investment. In other words, cities with a lower level of 
regional economic development can actually attract more investment because they have more potential for economic and market development. The positive correlation in the Beijing-Tianjin-Hebei urban agglomeration reflects the fact that the region's VC investment still has strong path dependence, and that entrepreneurial projects still play a limited role in changing the regional economic pattern.

3.2.3 Financial Strength $G F$ (level of financial environment development) has a weak negative influence on VC investment between cities.

The results in Table 3 show that the regression coefficient for Financial Strength GF (level of financial environment development) of cities in the Beijing-Tianjin-Hebei urban agglomeration is $\beta=0.0505$, with a significance of $p<0.05$, which indicates that it has a weak negative influence on VC investment between cities. This means that VC connections in the agglomeration are largely influenced by the information infrastructure development and economic development of each city, but they are not significantly related to whether a city has sufficient total financial institution deposits and loans and a developed financial environment. The level of deposits and loans of financial institutions and financial environment development, therefore, have a limited impact on regional patterns of $\mathrm{VC}$ investment.

3.2.4 Innovation Strength $G C$ and Service Strength $G S$ have a strong negative influence on $\mathrm{VC}$ investment between cities.

The results in Table 3 show that the regression coefficient for Innovation Strength $G C$ of cities in the Beijing-Tianjin-Hebei urban agglomeration is $\beta=-0.1440$, with a significance of $p<0.001$, and the regression coefficient for Service Strength $G S$ for cities in the agglomeration is $\beta=-0.2960$, with a significance of $p<0.05$, which indicates that Innovation Strength $G C$ and Service Strength $G S$ have a strong negative influence on VC investment between cities. This shows that there is a mismatch between the fruits of innovation and entrepreneurship and relevant service systems. Previous studies on the relationship between $\mathrm{VC}$ investment and technological innovation indicates that $\mathrm{VC}$ investment can improve the professionalism of human resources decision-making as well as market-value and stock-option choices, which produce a positive impact on a company's operations. Kortum and Lerner (2000), for example, looked at the influence of VC on patented inventions in the US and found that VC can promote market applications of technological achievements, and that $\mathrm{VC}$ investor networks can promote regional enterprise networks, which promote overall innovation. It can be seen, that $\mathrm{VC}$ is an important driving force for a company or city involved in technological innovation or industrial development, and patenting rates reflect the vitality and stability of a city's technological innovation. If the patenting rate is high, it indicates that a city has more innovations, and because these innovations are protected by patents, they have market value, making them ideal targets for VC. On the other hand, it can also indicate that a region has a sound system of legal protection for innovations, which reflects the industry standards and maturity of the market as a whole. Nevertheless, innovations have not received more $\mathrm{VC}$ in the Beijing-Tianjin-Hebei urban agglomeration, and there has been a weak negative correlation with development of the financial environment, similar to the development of the tertiary industry. This mismatch between innovation and VC very likely stems from the underdevelopment of associated facilities and services. 


\section{Conclusion and discussion}

Venture capital has become an important driving force of integration and innovation in the Beijing-Tianjin-Hebei urban agglomeration, and the spatiotemporal distribution of VC totals and density directly affect the formation and development of an integrated network within the agglomeration. There is a certain degree of cyclical fluctuations in total VC within the VC network of the Beijing-Tianjin-Hebei urban agglomeration, with the three VC centers (Beijing, Shijiazhuang and Tangshan) having a stimulatory effect on surrounding cities. VC flows between cities display certain networking rules, but they are slow to develop and strongly centripetal. The network connections between second-tier cities are still very weak. The use of a gravity model and an econometric model to look at influencing factors on this network's development showed that levels of information infrastructure development and economic development had strong positive influence on VC investment, but that cities with underdeveloped financial environments and service industries are less able to convert the fruits of innovation and entrepreneurship and to attract funds, displaying a weak correlation with VC investment. Investment connections within the VC network are highly complex, and the five variables that were incorporated are unable to fully explain the causes of their occurrence and development, especially in the case of some factors that are difficult to quantify but highly influential, such as policies, which require further research on how to incorporate them in a quantitative model. Moreover, there is still room for improvement in the selection of some variable indicators, such as financial environments. Data from shorter time intervals is also required to explain factors in special scenarios, so as to eliminate the impact of outliers on the overall changing trends.

\section{References}

Batten D F, 1995. Network cities: Creative urban agglomerations for the 21st century. Urban Studies, 32(2): 313-327.

Chen H, Gompers P, Kovner A et al., 2010. Buy local? The geography of venture capital. Journal of Urban Economics, 67: 90-102.

Fang Chuanglin, Mao Qizhi, 2015. The New Exploration of China's Urban Agglomeration Selection and Cultivation. Beijing: Science Press. (in Chinese)

Fang Chuanglin, Song Jitao, Lin Xueqin et al., 2010. Theory and Practice on the Sustainable Development of China's Urban Agglomeration. Beijing: Science Press. (in Chinese)

Fang Yelin, Huang Zhengfang, Tu Wei, 2013. Spatial differences of tourism economy in Yangtze River Delta from the perspective of social network. Tropical Geography, 33(2): 212-218. (in Chinese)

Green M B, McNaughton R B, 1989. Interurban variation in venture capital investment characteristics. Urban Studies, 26(2): 199-213.

Hellmann T, 2000. Venture Capitalists: The Coach of Silicon Valley, Chapter 13 in The Silicon Valley Edge. Lee Chong, Moon Miller et al. eds. Stanford: Stanford University Press.

Hou Yunhui, Liu Zhibiao, Yue Zhonggang, 2009. Social network analysis over the process of economic integration in the Yangtze River Delta. China Soft Science, (12): 90-101. (in Chinese)

Ji Lingzhu, 2007. Research on regional cluster and factors of venture capital in China [D]. Hangzhou: Zhejiang University. (in Chinese)

Kortum S, Lerner J, 2000. Does venture capital spur innovation? Rand Journal of Economics, 31: 674-692. 
Li Xiang, 2011. Research on the Yangtze River Delta urban agglomeration network structure based on social network analysis. Urban Studies, 12: 80-85. (in Chinese)

Liu Jun, 2014. Lectures on Whole Network Approach: A Practical Guide to UCINET. Shanghai: Shanghai People's Press. (in Chinese)

Liu Yaobin, Dai Lu, 2013. Economic contact analysis with network structure of urban agglomeration around the Poyang Lake based on SNA. Resources and Environment in the Yangtze Basin, 22(3): 263-271. (in Chinese)

Lu Jingping, Yang Zhenwu, Liu Yu, 2015. Economic network in Beijing-Tianjin-Hebei urban agglomeration. Inquiry into Economic Issues, (5): 117-122. (in Chinese)

Parr J, 2010. The polycentric urban region: A closer inspection. Regional Studies, 38(3): 231-240.

Qiu Juan, 2012. Urban distribution and network research of venture capital investment in China [D]. Nanjing: East China Normal University. (in Chinese)

Wang Mingfeng, Wei Yehua, Qiu Juan, 2014. Spatial agglomeration and urban network of venture capital investment in China. Journal of Finance and Economics, (4): 117-131. (in Chinese)

Wang Yanjun, Zong Yueguang, Ouyang Li et al., 2011. Social network analysis on the process of economic coordination in the Guanzhong-Tianshui Economic Zone. Areal Research and Development, 30(6): 18-21. (in Chinese)

Zhang J, 2011. The spatial dynamics of globalizing venture capital in China. Environment and Planning A, 43(7): 1562-1580.

Zhao Miaoxi, Wei Jiming, Wu Kang, 2014. Functional linkages in the Beijing-Tianjin-Hebei conurbation region and the evolution of the complex networks. Urban Planning Forum, (1): 46-52. (in Chinese) 